\title{
Accelerometer Based Stair Climbing in Healthy Subjects: Reference Data and Demographic Differences
}

\author{
Verlaan L*, Storken G, Heyligers IC and Grimm B \\ Department Orthopaedics \& Traumatology, Zuyderland Medisch Centrum, Netherlands
}

Submission: January 28, 2019; Published: February 11, 2019

*Corresponding author: L Verlaan, Department Orthopaedics \& Traumatology, Zuyderland Medisch Centrum, Henri Dunantstaat 5, 6419 PC Heerlen, The Netherlands

\begin{abstract}
Background: Accelerometers facilitate analysis outside traditional gait laboratories. Before using these devices on a larger scale and in clinical settings, a thorough assessment of their performance in diverse populations is required. The goal of this study was to present an acceleration-based reference database for stair climbing in healthy subjects. The effect of age was studied with different parameters, such as step time up and down, asymmetry and irregularity.
\end{abstract}

Methods: Our study included 100 healthy subjects, which were divided in two age groups. The group of younger adults consisted of 54 subjects with a mean age of 26 years and the group of older adults consisted of 46 subjects with a mean age of 65 years.

Findings: Average step times were slightly higher ascending compared to descending. Step time difference, between ascending and descending, was significant between the young and elderly group. Irregularity and asymmetry did not diverge between the age groups. In addition, effects of age on gait parameters were found to be consistent with those reported in studies using other methodologies.

Interpretation: Stair climbing based findings together with all the advantages of the device support the application of accelerometerbased gait analysis for routine clinical use and in daily life.

Keywords: Stair climbing; Accelerometer; Demographic differences; Reference data

Abbreviations: $\mathrm{t}_{\mathrm{up}}$ : Average Step Time Up; $\mathrm{t}_{\mathrm{down}}$ : Average Step Time Down; $\mathrm{t}_{\mathrm{up}}-\mathrm{t}_{\mathrm{down}}$ : Difference Between the Average Step Time Up and Down; irrup: Irregularity Up; irrdown: Irregularity Down; $\operatorname{asym}_{\mathrm{up}}$ : Asymmetry Up; asym $_{\mathrm{down}}$ : Asymmetry Down

\section{Introduction}

Over the years, patient expectations regarding the outcome of orthopaedic surgery have changed significantly. At this moment a high functional improvement (e.g. sport) is expected, while previously patients were satisfied when having less pain and an increased mobility. Next to this there is a demand for shorter hospitalization, for which faster rehabilitation and higher mobility levels are required [1].

To diagnose and postoperatively monitor these ever more demanding orthopaedic patients, it becomes increasingly important to objectively measure function. At present function and mobility of patients are clinically evaluated by questionnaires and visual assessment, producing mainly subjective and mostly pain related functional results $[2,3]$. Objective and more accurate techniques such as video-based gait analysis, force platforms and EMG, are mainly used in research settings only. Unfortunately, these techniques are less suitable for routine clinical application because of high costs and complexity demanding designated space, personnel and long set-up times. Furthermore, a lot of studies take place in laboratory settings creating an unusual situation $[4,5]$.

Motion analysis using body-fixed accelerometers is less capacious but its relative simplicity, its low cost and ease of operation make it suitable for routine clinical application. The less rich data output with few basic parameters may even be seen as an advantage in clinical practice where it aims to be used as a complementary scale for outcome scoring instead of a sophisticated motion analysis requiring expert interpretation. Accelerometer derived motion parameters were clinically validated for normal gait in healthy subjects [6]. Lately accelerometer-based gait analysis has come forward as a potential partial alternative for conventional gait analysis because of its high reliability in analyzing gait parameters and lower limb motion $[7,8]$. Various clinically relevant gait parameters, such as cadence and walking variability, can simultaneously be 
obtained from acceleration signals by autocorrelations or peak detection algorithms [9-11]. However, gait was identified as not demanding enough to distinguish finer functional differences. Then again stair climbing is an important and common functional activity that may be a more informative clinical evaluation procedure than level walking for patients with disorders of the lower extremity [12]. Consequently, stair climbing may produce more sensitive motion parameters with accelerometerbased motion analysis. To make inertia-based motion analysis with accelerometers applicable for clinical evaluation a reference database for healthy stair climbing is required. Another complementary aspect regarding to questionnaires is the possibility of testing functional improvement more accurately. Whereas a questionnaire has a maximum score, the accelerometer can measure functional improvement without reaching a ceiling effect. This makes them perfectly applicable for routine orthopaedic follow-up. A standard hospital stair with normal surroundings, without intimidating equipment etc, provides a more natural environment to measure stair climbing

\section{Materials and Methods}

\section{Subjects}

Table 1: Demographics of subjects categorized by decade of age (averages and standard deviations).

\begin{tabular}{|c|c|c|c|c|c|c|}
\hline & F : M & Age [yrs] & Height [cm] & Weight [kg] & BMI [kg/m $\left.{ }^{2}\right]$ & Dominant side (right: left) \\
\hline Total n: 100 & $64: 36$ & $44( \pm 21)$ & $171( \pm 9.8)$ & $70( \pm 12)$ & $24( \pm 3.3)$ & $87: 13$ \\
\hline Young n: 54 & $34: 20$ & $26( \pm 17)$ & $175( \pm 21)$ & $69( \pm 22)$ & $22( \pm 5.9)$ & $46: 08$ \\
\hline Old n: 46 & $30: 16$ & $65( \pm 8.0)$ & $167( \pm 9.2)$ & $72( \pm 13)$ & $26( \pm 3.4)$ & $41: 05$ \\
\hline
\end{tabular}

Only healthy subjects were recruited into the study so that reference data for normal stair climbing could be collected. The health status was assessed in a standardised way using a selfmade questionnaire investigating the absence of any pathologies possibly affecting movements considered as normal. Excluding criteria were the presence of a musculoskeletal or neurological disorder, or any previous surgical intervention that could affect physical activity. Ascending and descending of stairs was measured in 100 volunteer subjects ( 64 females, 36 males) with a mean age of 44 years old (SD 21; range 17-81). The study group was divided in two age groups: a young group and an old group. The young group (n: 54: 34 females, 20 males) had a mean age of 26 years (SD 17; range 17-49) and the old group (n: 46: 30 females, 16 males) had a mean age of 65 years (SD 10; range 50 81) (Table 1). Other values recorded were height, weight, BMI and dominant side. Ethical approval and informed consent were obtained for all subjects.

\section{Equipment}

During the measurements the lower trunk accelerations were measured by a light weight triaxial accelerometer (size $62 \times 41 \times 18 \mathrm{~mm}$, weight $53 \mathrm{~g}, \mathrm{f}=100 \mathrm{~Hz}$, range: $2 \mathrm{~g}$, McRoberts BV, The Hague, The Netherlands [9]. The accelerometer was attached tightly with a belt to the sacrum, which produced the most reliable accelerometer signals [13-15]. Data was stored than the usual laboratory setting. To conduct a single stair test, including setup, measurement and analysis, may take as little as $10 \mathrm{~min}$, permitting the examination of several subjects in a relatively short time period. In addition, accelerometer-based gait analysis can be used for quick analysis of multiple steps, which allows us to test fluctuations in gait pattern during stair climbing resulting in the measurement of different variables such as symmetry and regularity.

\section{This study}

a) investigates whether a stair climbing test with accelerometer derived motion parameters is clinically feasible,

b) investigates whether this test is capable to identify differences between demographic groups of healthy subjects and

c) documents a reference database for stair climbing in healthy subjects. on a local memory card (256MB). The unit was powered by two AAA1.5V batteries.

\section{Protocol}

Subjects ascended and descended five stairs two times at preferred, comfortable speed and were not allowed to use the handrails during stair climbing. The stairs consisted of 10 stairs with step dimensions of $18 \mathrm{~cm}$ (riser height) by $29 \mathrm{~cm}$ (tread). Subjects were requested to wear shoes with flat soles. We started with ascending five stairs, followed with a rest of 3 seconds. Next the five ascending stairs were completed. The last ascending stair was finished with standing feet together and a rest period of 3 seconds, followed by turning around, standing feet together and again a rest period of 3 seconds. Descending stairs was measured according to the same procedure as ascending the stairs. A whole measurement had a maximum duration of 30 seconds.

For the reproducibility and inter-rater reliability, the measurement was repeated one week later with another observer under the same circumstances.

\section{Data analysis}

Raw data was downloaded to a PC using specific software (Mira 1.9 Beta, McRoberts BV, The Hague, The Netherlands [9]. Based on the principles to detect steps of level walking [11], 
several motion parameters were derived for acceleration peak detection algorithms in Matlab 7.1 (Mathworks, USA): first the average step time up and down (tup, tdown) defined as the time per step up and the time per step down in msec. Second, the difference between the average step time up and down (tup-tdown). Third, irregularity up and down (irrup, irrdown) defined as the difference between maximum and minimum step times. Fourth, the asymmetry up and down (asymup, asymdown) described as the difference between the step times of the dominant and non-dominant leg. Taken into account that the first and the last step were part of the start and ending phase, and that they did not occur in a fluent motion, only data of the second, third and fourth step per five-step flight were analysed. Moreover, stair test parameters were compared for age differences, and correlated to subject demographics such as gender and BMI.

\section{Statistical analysis}

Inter-rater reliability was evaluated for each parameter using Intra Class Correlation coefficients (ICC). ICCs $>0.75$, between $0.40-0.75$, and $<0.40$ were interpreted respectively as an excellent, fair-to-good and poor reliability [9]. Age group comparison were performed using independent samples t-test and subject demographics correlations were examined using Pearson's R $(\mathrm{p}<0.05)$. All statistics was performed using SPSS version 15.0.

\section{Results}

\section{Reliability and reproducibility}

Average values for most stair test parameters were similar across two sessions. T-tests showed no significant differences $(p<0.05)$ in any of the stair parameters between both measurement days, indicating that climbing stairs was similar over time. Inter-rater reliability was very good for Tup, Tdown and Tup-down, respectively $0.94,0.97$ and 0.81 and fairly good for irregularity up (0.61) and down (0.73).

\section{Step time up and down}

Table 2: Stair climbing parameters [ms] overall and per age group $\left({ }^{*} p<0.01\right)$.

\begin{tabular}{|c|c|c|c|c|c|c|}
\hline [ms] & Avg & SD & Min & Max & Young & Old \\
\hline tup & 613 & 71 & 470 & 888 & 592 & $638^{*}$ \\
\hline tdown & 594 & 114 & 428 & 1172 & 543 & $654^{*}$ \\
\hline $\begin{array}{c}\Delta \text { tup- } \\
\text { tdown }\end{array}$ & 19 & 65 & -287 & 103 & 49 & $-16^{*}$ \\
\hline Irrup & 121 & 49 & 40 & 260 & 123 & 119 \\
\hline Irrdown & 123 & 48 & 50 & 250 & 118 & 129 \\
\hline Asymup & 49 & 35 & 2 & 138 & 50 & 40 \\
\hline Asymdown & 39 & 29 & 0 & 113 & 30 & 50 \\
\hline
\end{tabular}

In all subjects combined, average step times, mean $604 \mathrm{~ms}$ (SD 106), were slightly higher ascending, mean tup 613ms (SD 71), compared to descending, mean tdown 594ms (SD 114), $\mathrm{p}<0.05$, Table 2 . This difference was visible for most individuals $(76 / 100)$. The step time difference between ascending and descending was $19 \mathrm{~ms}$ (SD 65), with a significant difference $(p<0.01)$ between the young (tup-tdown=49ms) and elderly group taking on average more time to descend $(-16 \mathrm{~ms})$. All subjects with descending times at least $20 \mathrm{~ms}$ slower than ascending $(19 / 100)$ were found in the elderly group $(p<0.01$, figure 1). Furthermore, correlations between step times and demographic parameters gender and BMI were calculated. Step time up $(\mathrm{p}<0.05)$ and step time down $(\mathrm{p}<0.01)$ correlated significantly with BMI while no correlations were found between gender and step times. Additional t-tests illustrated that subject with a higher BMI ( $>25$ ) showed significantly higher step times down $(\mathrm{p}<0.01)$ and almost significantly step times up $(\mathrm{p}=0.06)$.

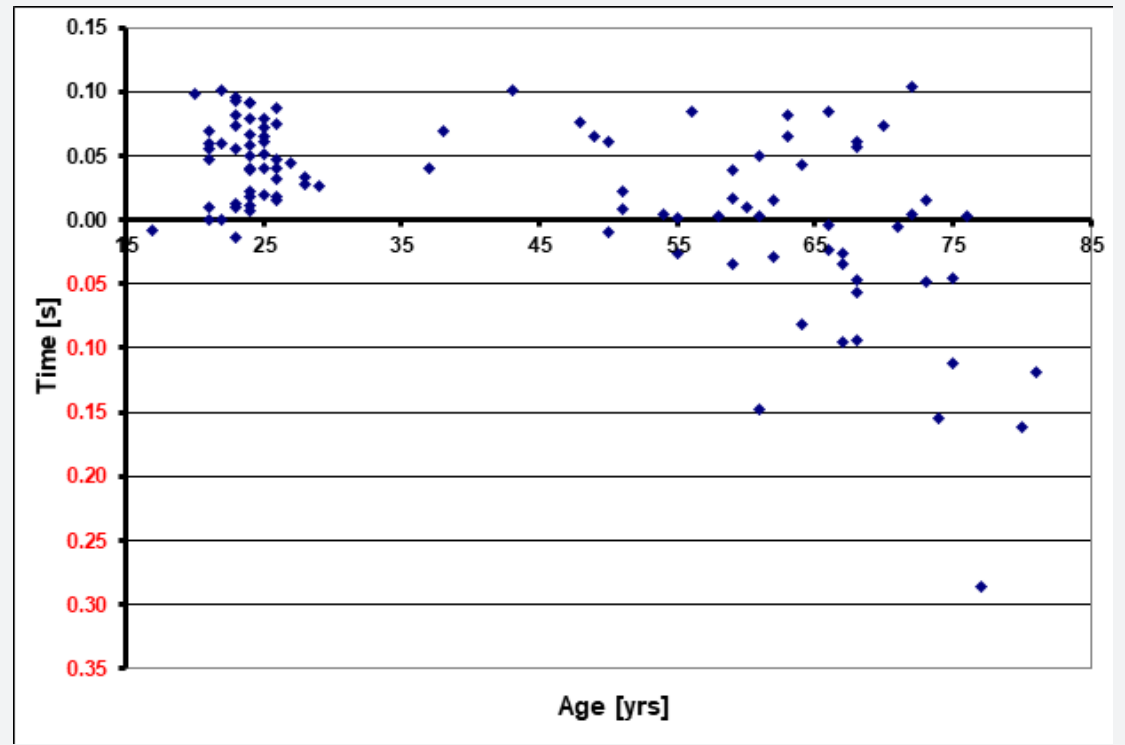

Figure 1: Average difference step time up minus down vs. age. Dotted line is threshold tup-tdown $=-0.02 s$. 


\section{Irregularity and asymmetry}

Irregularity was nearly equal for ascending, mean $121 \mathrm{~ms}$ (SD 49), and descending, mean 123ms (SD 48). Between age groups no differences were found in irregularity for ascending, young mean 123ms (SD 107); old mean 119ms (SD 47), and descending, young mean 118ms (SD 96); old mean 129ms (SD 48). Next to this, asymmetry did not show large differences between stepping up, mean 49ms (SD 35), and stepping down mean 39ms (SD 29). Furthermore, no differences were found between age groups in asymmetry (ascending, young vs. old: 50 vs. $40 \mathrm{~ms}$ and descending, young vs. old: 30 vs. $50 \mathrm{~ms}$ ). However, asymmetry revealed that steps with the dominant leg were of equal or faster speed than the non-dominant leg in 43/46 cases ascending and $39 / 46$ cases descending. Moreover, no correlation was found between irregularity and the demographic parameters gender and BMI.

\section{Discussion}

The purpose of this study was to investigate whether a stair climbing test with accelerometer derived motion parameters in a group of healthy subjects is clinically feasible and valid to distinguish between demographic differences. Our findings confirmed that the accelerometer can provide good and reproducible measurement of temporal stair climbing parameters in healthy subjects in daily life, non-laboratory situations.

The high inter-rater reliability shows that there is acceptable consistency between different stair walks of individual subjects and between different observers taking the test, a common scenario in routine clinical outcome assessment. Inter-observer variability may come from sensor placement, patient instruction and data analysis all of which still have improvement potential such as using even smaller sensors with direct to skin fixation, to use a standard instruction video or perform fully automated signal analysis. Furthermore, our study $(\mathrm{N}=100)$ contained a much larger sample size, than comparable studies of Stacoff et al. [16] $(\mathrm{N}=20)$ and of Riener et al. [5] $(\mathrm{N}=10)$.

Average step times up were higher than step times down as expected by the difference in energy expenditure. Individuals with slower step times down were all elderly indicating that a loss of or fear of falling compensates the benefits of an energetically less demanding movement. Moreover, fear of falling plays an important factor in stair climbing because the largest proportion of falls in elderly people was reported to occur on stairs [17]. Especially in descending stairs, accidents occur about three times more frequently while descending stairs than ascending stairs [18]. Hsu et al. [19] found that older adults developed different strategies for stair descent than younger adults [19]. One of the strategies included an increased support time at the push-off phase, which suggested that the step time down for elderly will increase in comparison with younger people. This was mentioned by Stacoff et al. [16] that older people compared with younger people walked with significant lower speed during stair climbing. No differences were found between age groups in ascending and descending the stairs, which could be due to the small number of subjects per age group (20 subjects divided over three groups. Above that, they concluded that age seems to be a factor which should be taken in consideration. This matches with our findings, which demonstrated a strong significant difference in descending the stairs between age groups.

In addition, Stacoff et al. [16] found in twenty healthy subjects longer step times for ascending, increasing from $692 \mathrm{~ms}$ to $741 \mathrm{~ms}$ with increasing step height with riser heights: $13.3 \mathrm{~cm}$ (flat), $17.1 \mathrm{~cm}$ (standard) to $20.0 \mathrm{~cm}$ (steep). Descending step times varied from $612 \mathrm{~ms}$ to $644 \mathrm{~ms}$. They found longer step times for ascending, varying from $692 \mathrm{~ms}$ for flat up to $741 \mathrm{~ms}$ for steep up, then step times for descending, varying from $612 \mathrm{~ms}$ for flat down to $644 \mathrm{~ms}$ for steep down. The differences with our step times results are small, with slightly faster times determined for both ascending and descending. Besides different subject demographics and health status in comparison to our study, this may be an effect of different step heights and depths used as well as differences in the instructions with regards to the speed. The comparison of age groups in their study revealed that in general subjects of the young group (mean age: $33.7 \mathrm{yrs}$ ) were faster in all test conditions step heights, both up and down, than those of the old group (mean age: 76.5yrs), except for the standard stair ascent and the steep stair descend [16]. Riser height used in our study is comparable with standard height used in the study of Stacoff et al. [16] $(18.0 \mathrm{~cm}$ vs $17.1 \mathrm{~cm})$.

Although not the focus of this study, the relation between step times and BMI seem to reflect that adults with an increased BMI become slower on stair walking [20]. These findings may suggest an association between increased BMI and mobility disability. This latter association was described for older adults in a recent review [21].

In the contrary to step times, overall asymmetry and irregularity during stair ascending and descending did not change between young and old. This can be an effect of testing healthy people without pathologies. Testing 'unhealthy' subjects, especially with unilateral pathologies such as meniscal tear, would be likely to show difference between asymmetry and irregularity.

However, steps taken with the dominant leg tend to be faster than with the non-dominant leg in most of the cases, no difference in gait asymmetry was proven, as mentioned earlier. In the past only one study confirmed that asymmetry during stair climbing increases in stair descending [16], where others could not [22]. The functional asymmetry during gait does not necessarily appear to be the consequence of abnormality, but rather relates to the different tasks of limbs, i.e. limb dominance [22]. At the same time, asymmetry clearly identified the strength of the dominant leg indicating its potential as a powerful 
parameter to detect and monitor unilateral pathologies such as meniscal tear. Unfortunately, results of the asymmetry were only registered in the first 46 subjects.

For normal gait Senden et al. [6] already validated the accelerometer in healthy subjects. They found significant effects of gender on step time and speed. However, contrarily to our study, no significant differences were observed between age groups. Compared to normal gait, stair climbing requires a larger effort, which can explain the difference in step time during stair climbing between young and old. In elderly, fatigue could be a factor of influence when using a standard stair instead of a shorter staircase.

Although step times and step time-based parameters such as asymmetry and irregularity have been proven as reliable and valuable motion parameters which are easy to measure, they provide limited information. In future we aim to extend the analysis of the acceleration signal to other non-temporal stair climbing parameters (e.g. dynamic sway) or use 3D gyrometers for a richer signal.

\section{Conclusion}

With a test duration of $<30$ s and reproducible, sensitive parameters, the acceleration- and step time-based stair test is a functional assessment suitable for routine clinical follow-up and to complement classic questionnaire-based scores. The test can distinguish stair climbing performance between young and old healthy subjects, which extends previous comparable studies on normal gait. Furthermore, the test can detect the dominant leg indicating its diagnostic potential in pathological motion especially in unilateral pathologies encountered in orthopaedics such as joint replacement. The relatively large number of healthy subjects tested in this study provides reference data for future studies on the test's diagnostic potential to identify specific pathologies, such as for instance meniscal tears.

\section{Acknowledgement}

This study was not sponsored. The study design, the data collection, the analysis and interpretation of data the writing of the manuscript was done independent.

\section{References}

1. Elgar FJ, Worrall G, Knight JC (2002) Functional assessment of elderly clients of a rural community-based long-term care program: A 10-year cohort study. Can Jon aging-revue vandienne du vieillissement 21(3): 455-463.

2. Brunnekref JJ, van Uden CJ, van Moorsel, Kooloos JG (2005) Reliability of videotaped observational gait analysis in patients with orthopaedic impairments. BMC-Musculoskelet Disord 6: 17-26.

3. Salch M, Murdoch G (1985) In defence of gait analysis. Observation and measurement in gait assessment. J Bone Joint Surg Br 67(2): 237-241.

4. Reid SM, Graham RB, Costigan PA (2010) Differentiation of young and older adult stair climbing gait using principal component analysis. Gait Posture 31(2): 197-203.
5. Riener R, Rabuffetti M, Frigo C (2002) Stair ascent and descent at different inclinations. Gait Posture 15(1): 32-44.

6. Senden R, Grimm B, Heyligers IC, Savelberg HHCM, Meijer K (2009) Acceleration-based gait test for healthy subjects: Reliability and reference data. Gait Posture 30(2): 192-196.

7. Maffiulett NA, Gorelick M, Kramers-de Quervain I, Bizzini M, Munzinger JP, et al. (2008) Concurrent validity and intrasession reliability of the IDEEA accelerometry system for the quantification of spatiotemporal gait parameters. Gait Posture 27(1): 160-163.

8. Mackey AH, Scott NS, Walt SE (2008) Reliability and validity of an activity monitor (IDEEA) in the determination of temporal-spatial gait parameters in individuals with cerebral palsy. Gait Posture 28(4): 634639.

9. Brandes M, Zijlstra W, Heikens S, Lummel van R, Rosenbaum D (2006) Accelerometry based assessment of gait parameters in children. Gait and Posture 24(4): 482-486.

10. MoeNilssen R, Helbostad JL (2004) Estimation of gait cycle characteristics by trunk accelerometry. J Biomech 37(1): 121-126.

11.Zijlstra W, Hof AL (2003) Assessment of spatio-temporal gait parameters from trunk accelerations during human walking. Gait Posture 18(2): 1-10.

12. Yu B, Kienbacher T, Growney ES, Johnson ME, An KN (1997) Reproducibility of the kinematics and kinetics of the lower extremity during normal stair-climbing. J Orthop Res 15(3): 348-352.

13. Moe-Nilssen R (1998) Test-retest reliability of trunk accelerometry durig standing and walking. Arch Phys Med rehabil 79(11): 13771385.

14. Hendriksen M, Lund H, Moe Nilssen R, Bliddal H, Danneskiod-Samsoe B (2004) Test-retest reliability of trunk accelerometric gait analysis. Gait Posture 19(3): 288-297.

15. Menz HB, Lord SR, Fritzpatrick RC (2003) Acceleration patterns of the head and pelvis when walking on level and irregular surfaces. Gait Posture 18(1): 35-46.

16. Stacoff A, Diezi C, Luder G, Stussi E, Kramers-de Quervain IA (2005) Ground reaction forces on stairs : effects of stair inclination and age. Gait and Posture 21(1): 24-38.

17. Verghese J, Wang C, Xue X, Holtzer R (2008) Self-reported difficulty in climbing up or down stairs in nondisabled elderly. Arch Phys Rehabil 89(1): 100-104.

18. Liikavainio T, Isolehto J, Helminen HJ, Perttunen J, Lepola V, et al. (2007) Loading an gait symmetry during level and stair walking in asymptomatic subjects with knee osteoarthritis: importance of quadriceps femoris in reducing impact force during heel strike? The Knee 14(3): 231-238.

19. Hsu MJ, Wei SH, Yu YH, Chang YJ (2007) Leg stiffness and electromyography of knee extensors/flexors: comparison between older and younger adults during stair descent. J Rehab Res Dev 44(3): 429-436.

20. Apovian CM, Frey CM, Wood GC, Rogers JZ, Still CD, et al. (2002) Body mass index and physical function in older women. Obes Res 10(8): 740-747.

21. Vincent HK, Vincent KR, Lamb KM (2010) Obesity and mobility disability in the older adult. Obesity reviews 11(8): 568-579.

22. Bertucco M, Cesari P (2009) Dimensional analysis and ground reaction forces for stair climbing: Effects of age and task difficulty. Gait Posture 29(2): 326-331. 
This work is licensed under Creative Commons Attribution 4.0 License

DOI: 10.19080/JOJCS.2019.09.555771
Your next submission with Juniper Publishers will reach you the below assets

- Quality Editorial service

- Swift Peer Review

- Reprints availability

- E-prints Service

- Manuscript Podcast for convenient understanding

- Global attainment for your research

- Manuscript accessibility in different formats

( Pdf, E-pub, Full Text, Audio)

- Unceasing customer service

Track the below URL for one-step submission https://juniperpublishers.com/online-submission.php 